
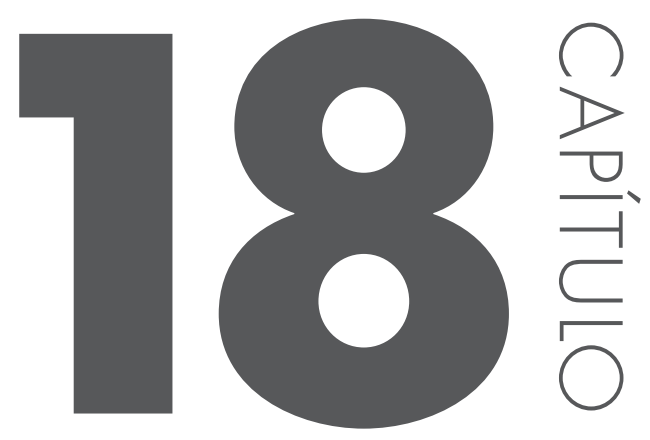

\title{
AS CRIANÇAS DE O A 6 ANOS NAS POLÍTICAS EDUCACIONAIS NA MICRÓRREGIÃO DE CATALÃO - GO
}

\author{
Abadia da Silva, Altina ${ }^{1 *}$; de Andrade Silva Ximenes, Priscilla ${ }^{2}$ \\ 1 Professora doutora da Faculdade de Educação da Regional Catalão-UFG. Professora \\ do Programa de Pós-Graduação em Educação - PPGEDUC - Linha de Pesquisa: Práticas \\ Educativas, Políticas Educacionais e Inclusão \\ ${ }^{2}$ Mestranda do Programa de Pós-Graduação em Educação - PPGEDUC - do Departamento \\ de Educação da Regional Catalão-UFG. Linha de Pesquisa: Práticas Educativas, Políticas \\ Educacionais e Inclusão \\ * email: priteducadora@hotmail.com
}

\section{RESUMO}

O presente trabalho apresenta recorte de uma pesquisa em andamento que está sendo desenvolvida no Programa de pós-graduação em Educação da Universidade Federal de Goiás/Regional Catalão e tem como objetivo discutir a educação infantil no contexto das políticas de atendimento a infância na microrregião de Catalão (GO). Inicialmente o texto trata das políticas de atendimento a infância e adolescência e discute a educação infantil no cenário político. Focaliza, em seguida, a formação de profissionais de educação infantil, um dos maiores desafios das políticas educacionais, 
bem como o perfil do município. No terceiro item, analisa o processo de municipalização da Educação Infantil em Catalão - GO.

Palavras-chave: Educação infantil; Formação de professores; políiticas educacionais.

Revisado pela Orientadora Atina abadia da Silva, contato: tina@wgo.com.br Inovação da Regional Catalão (2. : 2014 : Goiás) Coletânea Interdisciplinar em Pesquisa, Pós-Graduação e Inovação Volume 2 : Humanidades e Letras. Anais [livro eletrônico] / organizado por Adriana Freitas Neves, Idelvone Mendes Ferreira, Maria Helena de Paula, Petrus Henrique Ribeiro dos Anjos. São Paulo: Blucher, 2015. ISBN: 


\section{INTRODUC̣ÃO}

O presente trabalho apresenta um recorte de uma pesquisa em andamento que está sendo realizada no Mestrado em Educação da Universidade Federal de Goiás/Regional Catalão e tem como objetivo discutir a educação infantil no contexto das políticas de atendimento a infância em Catalão (GO). Este estudo se vincula a um projeto maior desenvolvido pelo Núcleo de Estudos e Pesquisas e Infância e Educação (NEPIE), que possui vários subprojetos com temáticas ligadas à educação infantil. $\mathrm{O}$ projeto de pesquisa: Políticas e Serviços de atendimento a infância e adolescência na microrregião de Catalão - GO congrega os pesquisadores do Núcleo de Estudos e Pesquisa Infância e Educação - NEPIE, e visa subsidiar a discussão sobre o atendimento à infância e adolescência na microrregião de Catalão/GO. É um projeto "guarda-chuva" que busca compreender e situar as competências e o financiamento das políticas, programas e ações de âmbito federal, estadual e municipal dirigidos à criança e ao adolescente, especialmente nas áreas da saúde, educação, lazer e cuidados. A análise volta-se também para alguns desafios apontados pelo Estatuto da Criança e do Adolescente (ECA), sobretudo aqueles relativos a sugestões e estratégias de atendimento e financiamento para a ampliação dos gastos destinados à infância e adolescência.

Um dos objetivos específicos desse projeto "guarda-chuva" se desdobrou no projeto de pesquisa ora apresentado, cujos objetivos são: 1) reconhecer as demandas manifesta e reprimida por acesso a partir do detalhamento do número de crianças matriculadas nas redes pública e privada de Catalão; 2) identificar as responsabilidades e competências para a oferta de políticas e serviços de educação; 3) relacionar os investimentos públicos realizados em favor da educação infantil para o período compreendido entre 2000 e 2020; e 4) avaliar o investimento complementar das famílias e empresas da região com a Educação Infantil.

A educação de crianças com idades compreendidas entre zero e seis anos vem se constituindo permeada pelas mudanças históricas dos conceitos de infância e de educação e pelas mudanças na política educacional. Enquanto fato sócio-histórico, a constituição e as formas de trabalho das creches e pré-escolas precisam ser compreendidas a partir do ideário político acerca de como deve ser o atendimento às crianças de determinada camada sócioeconômica e das concepções teóricas que orientam o trabalho realizado, englobando, principalmente, os conceitos de educação, escola, criança e de desenvolvimento, presentes no processo de formação do professor. 
A Educação Infantil está prevista na Constituição Federal de 1988, composto de dez artigos, do artigo 205 ao 214, à Educação como sendo direito de todos e dever do Estado e da Família. A Educação Infantil, cuja atenção e responsabilidade foram atribuídas aos municípios por força da Constituição Federal de 1988 e da Lei de Diretrizes e Bases da Educação Nacional (LDB) 9394/96 está sob a responsabilidade do município em relação à aplicação dos recursos na Educação Básica e Fundamental ao determinar o percentual em $25 \%$ do orçamento público, sendo que desse montante $15 \%$ são destinados ao ensino fundamental, não esclarecendo o legislador constitucional o percentual para ser investido em pré-escolas e creches. No segundo capítulo da LDB 9394/94 trata-se desta etapa da Educação Básica, bem como traz os princípios básicos para o Plano Nacional de Educação criado em 2001.

Dentro da perspectiva dada à Educação Infantil pela legislação brasileira a partir da aprovação da Lei de Diretrizes e Bases 9394/96, se faz pertinente à escolha da Educação Infantil como um dos objetos de estudo do Núcleo. Analisando a importância da inclusão desta etapa do ensino à Educação Básica e o incentivo a municipalização deste atendimento, se torna notório a necessidade de uma discussão reflexiva sobre a situação estrutural e funcional destas instituições através de levantamentos quantitativos e qualitativos. Com uma estrutura de responsabilidades e competências, a Constituição Federal (CF) de 1988 estabeleceu que a educação deve ser considerada um direito social, definindo desta forma, a Família e o Estado como responsáveis pelo seu provimento. Visando assegurar o cumprimento da lei, visualizando a garantia de acesso e permanência do cidadão em uma instituição educacional de qualidade, este estudo buscou diagnosticar a realidade vivenciada na cidade de Catalão - GO e a sua relação com a garantia dos direitos constitucionais. $\mathrm{O}$ objetivo geral desta etapa da pesquisa se encontra em realizar um diagnóstico do atendimento referente à infância e adolescência na microrregião de Catalão - GO no que diz respeito ao acesso, qualidade e qualificação dos profissionais. Dentro deste projeto "guarda chuva" se encontram outros projetos de pesquisa e extensão realizados pelos pesquisadores do NEPIE em suas respectivas linhas, dentre eles o subprojeto "Perfil da educação infantil em Catalão - GO: indicadores de acesso e condições de oferta”, este estudo busca delinear o número de crianças de zero a cinco anos matriculadas nas redes pública e privada, considerando inclusive as crianças que não frequentam escola ou creche. Nesta perspectiva o estudo objetiva identificar as responsabilidades e competências no que tange ao atendimento a estas crianças, relacionado às políticas e serviços de educação e os investimentos públicos realizados em favor da Educação Infantil para o período compreendido entre 2000 e 2020. 
Oliveira (2002) alerta que a elaboração de leis e a definição de políticas públicas acontecem em um contexto social e político que envolve a sociedade civil e organizações governamentais. Portanto, a importância destinada à educação das crianças de 0 a 6 anos depende da conjuntura política e econômica e da relação de forças existentes na sociedade. Portanto, no que refere-se as políticas e serviços de atendimento a infância e adolescência há que se levar em conta a participação da sociedade civil e o envolvimento do governo, pois como nos alerta Arroyo:

uma das coisas mais ricas em nossa sociedade é o conjunto de lutas pelos direitos [...] o movimento social vai caminhando no sentido de definir, cada vez mais, grupos sociais com seus direitos, [...] e a infância avançou como tempo de direitos (ARROYO, 1994, p. 89).

Ao tratarmos dos Direitos da Criança e do adolescente é importante considerar que esta discussão ainda é recente no Brasil e que deve ser tratada como Direitos Humanos dessas crianças e adolescentes. As décadas de 1980 e 1990 tiveram importante representatividade nesta discussão, promovendo debates internacionais e se mobilizando para promover um diálogo na discussão sobre esses direitos que já estavam previstos na Declaração Universal dos Direitos Humanos (1949) em seu art.25, $\mathbb{S} 2^{\circ}$, ao afirmar que, “[...] A maternidade e a infância têm direito a cuidados e assistência especiais. Todas as crianças nascidas dentro ou fora do matrimônio, gozarão da mesma proteção.” Desta forma podemos visualizar que os direitos fundamentais de crianças e adolescentes já apareciam nas pautas internacionais desde a década de 1940 e que ao emergir a discussão no Brasil na década de 1980 não significou a indicação aleatória de um grupo etário específico entre os sujeitos de direitos, mas sim, que reconhecidamente foi dado um status especial a este grupo etário ao compreender que se trata de indivíduos que despendem maior atenção e proteção pela sua vulnerabilidade.

Nesta discussão proposta se faz imprescindível apresentar uma definição de Direitos Humanos para que possamos situar histórico e socialmente a emergência de políticas de valorização destes direitos e a criação de instrumentos efetivos de direitos para proteção das crianças. Neste contexto definimos os Direitos humanos como os direitos fundamentais da pessoa humana, pelo progressivo reconhecimento pelas nações e instrumentos internacionais, da inerente dignidade de todo indivíduo, independentemente de raça, sexo, idade ou nacionalidade. Os direitos humanos podem ser 
apresentados sobre dois aspectos: por um lado, constituem restrições ao poder do Estado, e por outro, condições mínimas para uma existência digna, asseguradas a todo indivíduo.

No que tange aos Direitos humanos da criança e do adolescente vemos que além de gozar de todos os direitos inerentes ao homem em sua sociedade, à criança e ao adolescente são garantidos o princípio da prioridade, no qual proteção e satisfação devem ser asseguradas pelo Estado antes de quaisquer outros, o que garante que dentre os direitos fundamentais, aqueles relativos à criança e ao adolescente deve vir em primeiro lugar. Esta particularidade atribuída aos direitos da criança e do adolescente está presente em diversos documentos internacionais, como a Declaração Universal dos Direitos das Crianças, de 1959, e a Convenção das Nações Unidas sobre os Direitos da Criança, de 1989. No Brasil temos o Estatuto da Criança e do Adolescente, de 1990 e a Política Nacional dos Direitos humanos de crianças e adolescentes e Plano Decenal dos direitos humanos de crianças e adolescentes (2011-2020).

Neste processo histórico pode-se perceber que a área que sofreu reformulações mais significativas, foi a área jurídica a partir da movimentação social de setores das ciências e práticas sociais para a promulgação do Estatuto da Criança e do Adolescente (ECA) em 1990. Para Rizzini (2000, p. 13) o ECA representa uma "[...] uma lei que, de certa forma, simboliza a revisão de paradigmas, que em relação ao entendimento da criança e do adolescente enquanto cidadãos, portadores de direitos e deveres.” Para a autora, o Estatuto da Criança e do Adolescente constitui um dos instrumentos que refletem as mudanças em curso sobre a forma de se conceber a criança no mundo de hoje. A criança e o adolescente a que se referem as leis atualmente são muito diferentes daqueles retratados como "menores" em passado recente (RIZZINI, 2000). Ao se referir as leis que retratam a criança e o adolescente como “menores”, Rizzini (2000) subentende o papel do Código de Menores no Brasil de 1927 e 1979, que tratavam o adolescente como menor infrator ou em situação irregular que deveria ser corrigido e punido a revelia da sociedade civil, já que o papel de punir cabia ao poder judiciário. Com a criação do ECA, no ponto de vista conceitual foi abandonado "[...] o paradigma da "infância em situação irregular" e adota o princípio de "proteção integral à infância" (BAZILIO, 2003, p.21), avançando desta forma na construção de um texto que amparasse todos os brasileiros menores de dezoito anos, independente de cor, raça, gênero ou condição social. O Estatuto propõe medidas protetivas, que amparam além das crianças e adolescentes em situação de risco ou vulnerabilidade social ou abandono, todas as crianças e adolescentes.

Como exposto anteriormente o Século XX abrigou momentos 
significativos de transformação institucional e de produção legal no Brasil, paralelamente viu-se surgir uma noção particular de infância e adolescência. Podemos citar a proclamação da Constituição Cidadã (1988), Estatuto da Criança e do Adolescente (1990) e a Lei de Diretrizes e Bases da Educação 9394 (1996). Esse movimento da sociedade demanda do Estado brasileiro e da sociedade política e civil esforços para garantir ações que promovam a continuidade e garantia desta ressignificação da sociedade no que tange a infância e adolescência para o século XXI, com vistas a assegurar políticas públicas de proteção e promoção e direitos (RIZZINI, NAIFF, BAPTISTA, 2006).

Neste contexto esta pesquisa se faz pertinente ao se tratar de um estudo voltado a análise e reflexão sobre as políticas de atendimento à criança e ao adolescente, estando em seu primeiro momento analisando o perfil da Educação Infantil de Catalão e Microrregião. A pesquisa tem caráter descritivo e analítico, centrado em pesquisa de campo e em análise documental realizado por pesquisadores de iniciação científica junto de seus orientadores. Como fontes de dados, nos valemos de estudos e levantamentos feitos pelo Inep e pelo IBGE. Outra fonte documental será o sitio da Secretaria Municipal de Educação de Catalão/GO. Quanto ao campo, estão sendo utilizados questionários direcionados à instituições educativas e entidades de proteção dos diretos da criança. Pretende-se usar as estimativas de crescimento necessário das matrículas da educação infantil, para adequá-las às metas de atendimento definidas pelo novo Plano Nacional de Educação (PNE, 2011/2020). Este estudo permitirá apontar sugestões de políticas governamentais, bem como opções e estratégias para aumentar a capacidade de financiamento para a Educação infantil, buscando responder à pergunta sobre a necessidade de revisão da política governamental de atendimento à infância.

\section{CONTEXTUALIZAC̣ÃO dO MUNICÍPIO de CATALÃo}

O município de Catalão está localizado ao extremo sudeste do Estado de Goiás; Situada ás margens da BR - 050, responsável pela ligação de Brasília ao Centro-sul; A Rodovia GO - 352 liga o município á capital do Estado; A base mais forte da economia é a Agricultura, seguida da Pecuária e nos últimos anos há um forte crescimento no número de médias e grandes empresas multinacionais do setor de Mineração, Beneficiamento e Armazenamento de grãos, Automotiva e Máquinas Agrícolas. De acordo com dados do censo 
referentes ao ano de 2014 a população total é de: 96.836 habitantes e seu PIB recenseado em 2011 são de mais de 4.851 .851 bilhões de reais. Os números referentes a demanda do atendimento aos anos iniciais, são os seguintes:

- $\mathrm{N}^{\circ}$ Total de Crianças de 0 a 4 anos: 5.223-7 79\% da população

- $\mathrm{N}^{\circ}$ Total de Crianças de 5 a 9 anos: 5.413

- $\mathrm{N}^{\mathrm{o}}$ de Crianças Atendidas em Escolas Públicas Educação Infantil: 1.840

- Projeção do número de crianças em 2006: 5.455

\section{DIAGNÓSTICO INICIAL DO CAMPO DA PESQUISA}

Partindo da legislação que apontava a Educação Infantil sob responsabilidade dos municípios, foi realizado um levantamento da situação estrutural e funcional deste nível de ensino. Deste modo, o objetivo central desta etapa da pesquisa era analisar a estrutura e o funcionamento da Educação Infantil na cidade de Catalão/GO. Seus objetivos específicos foram assim definidos: a) caracterizar o espaço físico/material e organizacional das instituições; b) identificar o número de profissionais que atuavam na Educação Infantil, bem como sua formação e nível de escolaridade; c) levantar os indicadores que orientavam o trabalho pedagógico nas instituições; d) criar um grupo de estudos. Para isso, foram estipulados tais procedimentos metodológicos: a) levantamento de dados genéricos sobre Secretaria Municipal de Educação, as instituições, alunos e profissionais; b) visitas e aplicações de questionários aos diretores das escolas de Educação Infantil; c) aplicação de questionário exploratório aos professores de Educação Infantil; d) aplicação de um questionário específico a alguns professores para o levantamento de informações didático-pedagógicas. Nos primeiros dois anos da pesquisa, foram sistematizados os dados referentes: a) á estrutura a funcionamento das 16 escolas públicas de Educação Infantil de Catalão-GO; b) á média de idade, formação e atuação de 65 professores. De posse destas informações, procedemos ás devidas análises. Tendo como eixo central do trabalho o processo de municipalização da Educação Infantil em Catalão-GO, foram apresentados e discutidos os dados quantitativos referentes aos seguintes aspectos: 
a) Oferta de atendimento;
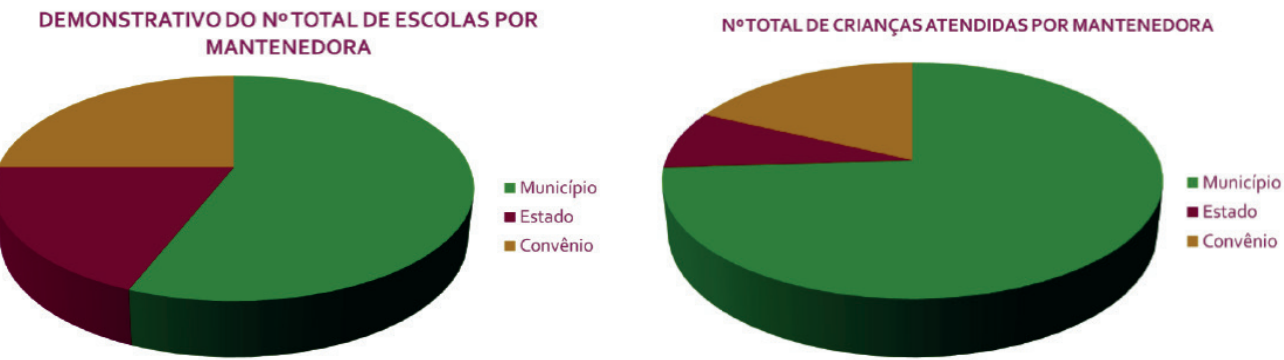

Fonte: Silva, Altina Abadia

Fonte: Silva, Altina Abadia

DEMONSTRATIVODAS IDADES ATENDIDAS POR ESCOLA

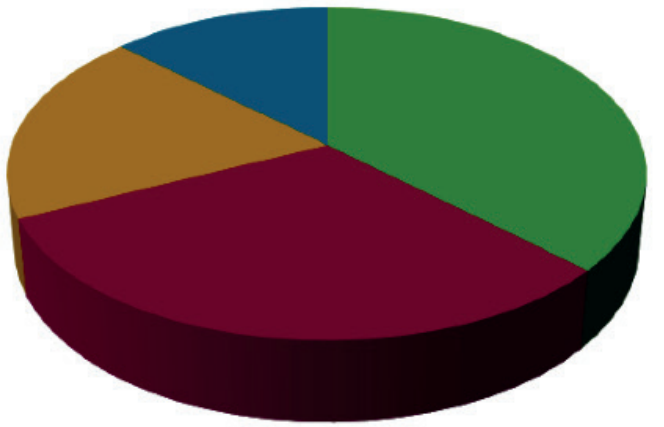

4 a 6 anos

- o a 6 anos

- $5 / 6$ anos

- 6 anos

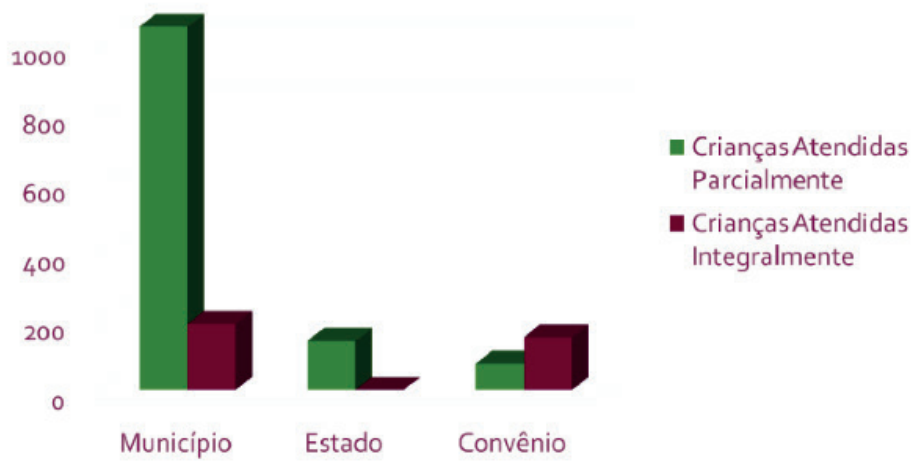

Fonte: Silva, Altina Abadia 


\section{DEMOSNTRATIVO DE NIVEIS DEATENDIMENTO PORMANIENEDORA}

$$
\begin{array}{r}
4,5 \\
4 \\
3,5 \\
3 \\
2,5 \\
2 \\
1,5 \\
1 \\
0,5 \\
0
\end{array}
$$

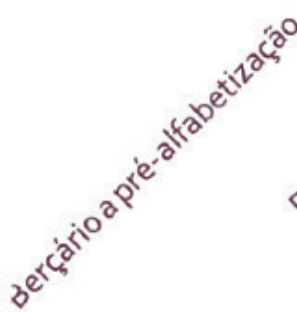

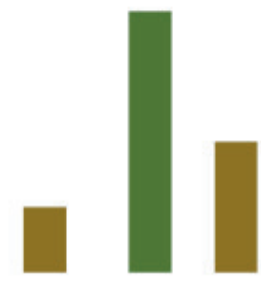

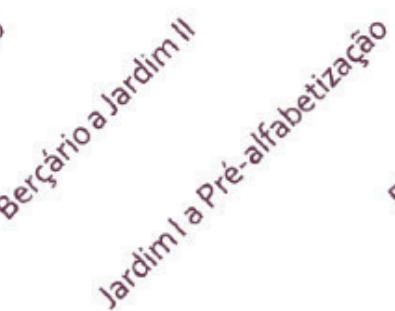

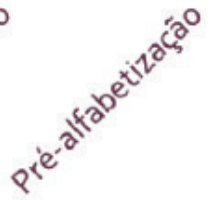

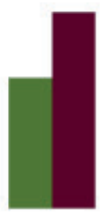

- Município

- Estado

convênio

Fonte: Silva, Altina Abadia

\section{DEMOSNTRATIVODE PERMANÊNCIAE EVASÃO POR MANTENEDORA}

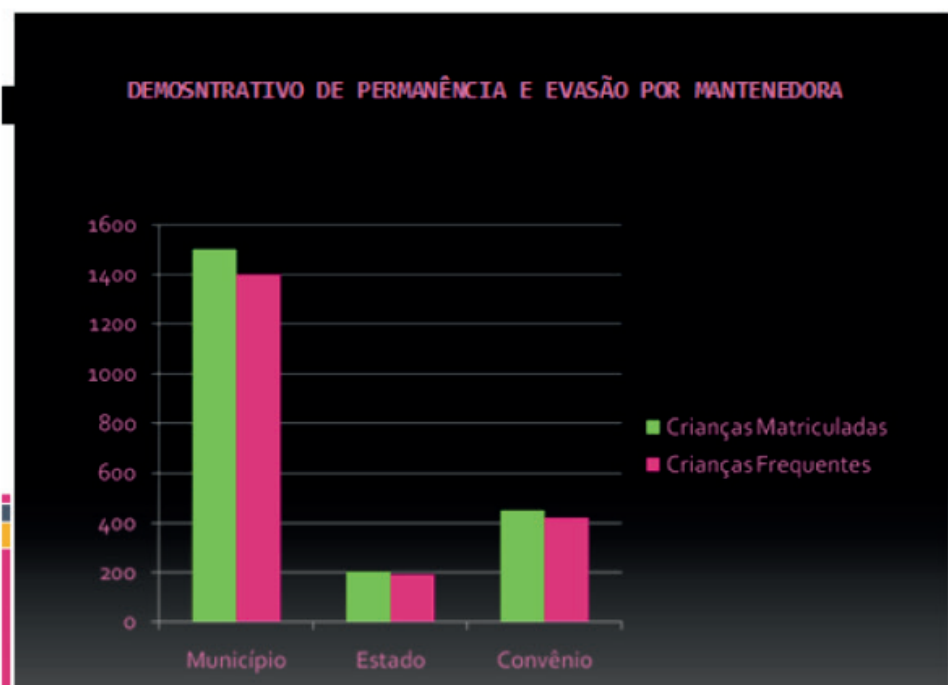

Fonte: Silva, Altina Abadia 
b) Formação/qualificação dos Professores.

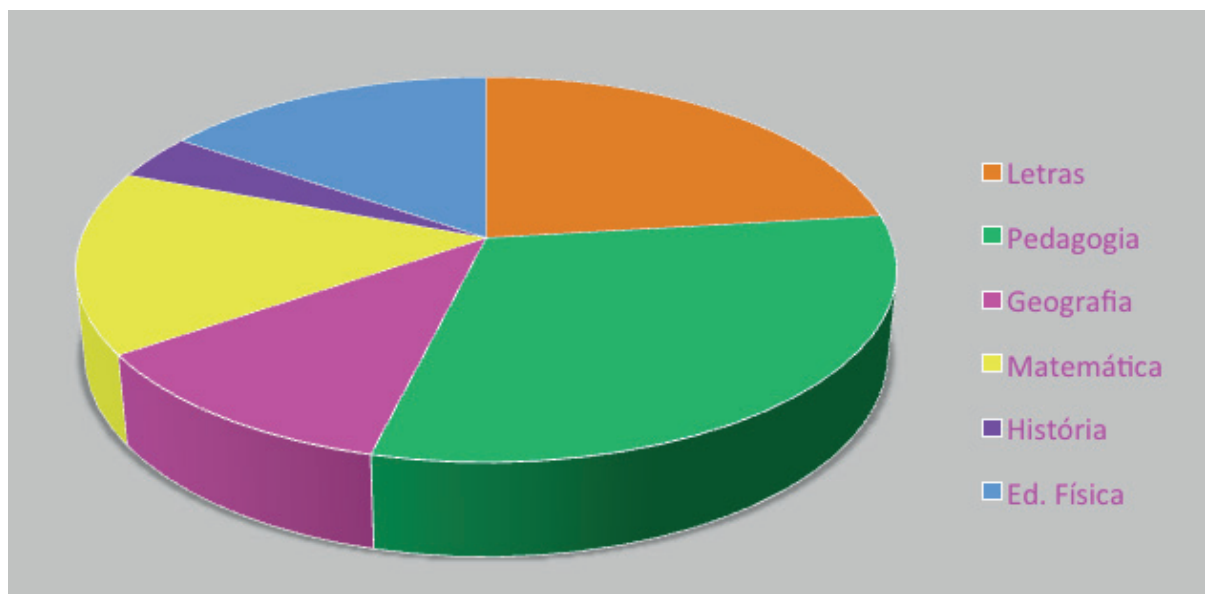

Fonte: Ximenes, Priscilla de Andrade Silva

DEMONSTRATIVODA MÉDIA DE IDADE DAS PROFESSORAS

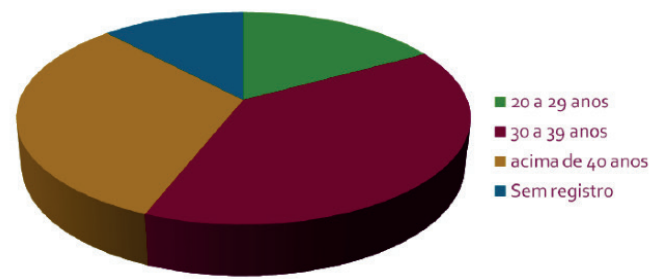

Fonte: Silva, Altina Abadia
DEMONSTRATIVO DOTEMPO DE ATUAÇÃONO MAGISTÉRIO

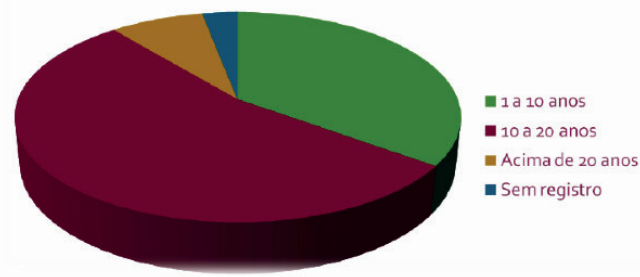

Fonte: Silva, Altina Abadia

No que tange a oferta de atendimento, os dados levantados apresentam a cristalização do processo de municipalização das escolas de Educação Infantil e dos anos iniciais no município, visto que o maior público atendido pelo município de Catalão está entre 0 a 6 anos. Os professores que atendem a Rede Municipal de ensino de Catalão tem formação em sua maioria no curso de Pedagogia, além de demais licenciaturas e grande parte do corpo docente atuam a mais de 10 anos no magistério. Alguns elementos ainda precisam ser apresentados referindo-se aos aspectos físicos e pedagógicos que estas instituições atendem, compreendendo que a garantia de permanência da criança na escola perpassa por condições adequadas do espaço físico, alimentação adequada e material didático-pedagógico coerente com a proposta de Educação Infantil. Estas variáveis fazem parte da continuidade da pesquisa que está em andamento. 


\section{Abstract}

This paper presents part of a research in progress which is being developed in the graduate program in Education, Federal University of Goiás/Regional Catalão and aims to discuss early childhood education in the context of childhood care policies in micro-Catalan (GO). Initially, the paper addresses the call childhood and adolescence policies and discusses childhood education in the political scene. Focuses, then the formation of early childhood professionals, one of the greatest challenges of education policies, as well as the city's profile. In the third, it explores the process of decentralization of early childhood education in Catalão - GO.

Keywords: Child rearing; Teacher training; education. 


\section{REFERÊNCIAS}

ARROYO, Miguel G. 0 significado da infância. In: I Simpósio de Educação Infantil. Brasilia, Ministério da Educação, 1994, p.88-92.

BECCHI, E. e BONDIOLI, A (Org). Avaliando a pré-escola: uma trajetória de formação de professoras. trad:

Fernanda Landucci Ortale e llse Carlos de Freitas. Campinas: Autores Associados, 2003.

BRASIL, Referencial Curricular Nacional para a Educação Infantil. Ministério da Educação e do Desporto, Secretaria de Educação Fundamental. Braślia: MEC/SEF, 1998. Vols. I, II e III.

BAZILIO, Luiz Cavalieri, KRAMER, Sônia. Infância, educação e direitos humanos. São Paulo: Cortez, 2003.

CARDONA, Maria J. Para a história da Educação de Infância em Portugal: 0 discurso oficial (1834-1990). Portugal, Ed. Porto, 1997.

CRAYDY, C. M; KAERCHER G. E da Silva (Org). Educação Infantil: pra que te quero? Porto Alegre: Arrmed Editora, 2001.

CRUZ, M. N. Palavras e Gestos no Jogo Interativo: um estudo dos processos de significação no cotidiano de um berçário de creche. Dissertação de Mestrado. Campinas, UNICAMP, 1995.

ELLAS, Norbert. A sociedade dos indivíduos. Rio de Janeiro: Jorge Zahar, 1994.

, Norbert. Os estabelecidos e os outsiders. Rio de Janeiro: Jorge Zahar, 2000.

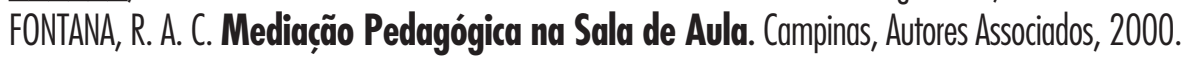

FORMOSINHO, Júlia de 0. (Org.). Modelos curriculares para a Educação da Infância. Portugal, Editora Porto: 1998.

GONCALVES, M. A. S. Sentir, pensar e agir. Campinas: Papirus, 1994. 10

JOBIM e SOUZA, S. Linguagem, consciência e ideologia: conversas com Bakhtin e Vygotsky. In: Oliveira, Z. M. R. (org.) A criança e seu Desenvolvimento - perspectivas para discutir a educação infantil. SP: Cortez, 1995. KRAMER, S. A política do Pré-escolar no Brasil: a arte do disfarce. São Paulo, Cortez, 2003.

LEITE, $M^{a}$., Isabel. Nem fase de grafismo, nem exerćício psicomotor: 0 desenho como espaço de produção cultural de crianças. In: MACHADO, Ma ., L. de A. (org.) Encontros e Desencontros em Educação Infantil. São Paulo: Cortez, 2002, p. 268-274.

MACHADO, M. L. de A (Org). Encontros e desencontros em educação infantil. São Paulo: Cortez, 2002.

MOSS, Peter. Reconceitualizando a infância: crianças, instituições e profissionais. In: MACHADO, Maria Lucia de A. (org.).

Encontros e desencontros em educação infantil. São Paulo: Cortez, 2002. p. 235-248.

NASCIMENTO, Telma. F. Norbet Elias: Algumas considerações. In: Fragmentos de Cultura. Goiânia, V. 14, n. 9, p. 1647-1655, set. 2004.

NUNES PINTO, R. Civilidade, corpo e escolarização da criança: o legado de Descartes e Rousseau. In: Revista Poiésis. Catalão/GO Vol. I N 1 jan./dez. 2003.

OLINDA, E. M. B. de. 0 conceito de formação integral no projeto formativo moderno: aprendendo com a experiência cearense. In. (Org.). Formação Humana: liberdade e historicidade. Fortaleza: Editora UFC, 2004. p. 118-135.

OLIVEIRA, Z. M. R. de. (Org.) Educação Infantil: muitos olhares. São Paulo: Cortez, 2000.

OLIVEIRA, Zilma de Moraes R. Educação Infantil: fundamentos e métodos. São Paulo: Editora Cortez, 2002. 
PINO, A. Editorial. Educação e Sociedade. Campinas, Cedes n. 71, 2000.

RIZZINI, Irene. Criança não é risco, é oportunidade: fortalecendo as bases de apoio familiares e comunitárias para crianças e adolescentes / Irene Rizzini, Gary Barker, Neide Cassaniga. Rio de Janeiro: USU Ed. Universitária: Instituto Promundo, 2000. $48 \mathrm{p}$.

UNICEF, CESPI/USU.

A Criança e a Lei no Brasil: Revisitando a História (1822-2000). Brasilia:

ROCHA, M. Silvia P. M. L. da. 0 real e o imaginário no faz-de-conta: questões sobre o brincar no contexto da pré-escola. In: GÓES, M․ Cecília R. de \& SMOLKA, Ana Luiza B. A Significação nos Espaços Educacionais: interação social e subjetivação. Campinas. Papirus, 1997.

VYGOTSKY, L. S. A Formação Social da Mente. São Paulo, Martins Fontes, 1994.

. Pensamento e Linguagem. São Paulo, Martins Fontes, 1991. Manuscrito de 1929. Educação e Sociedade. Campinas, Cedes n. 71, 2000. 